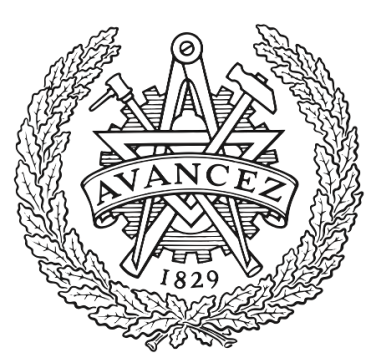

CHALMERS

UNIVERSITY OF TECHNOLOGY

\title{
Polycyclizations of Ketoesters: Synthesis of Complex Tricycles with up to Five Stereogenic Centers from Available Starting Materials
}

Downloaded from: https://research.chalmers.se, 2023-04-26 06:02 UTC

Citation for the original published paper (version of record):

Kamlar, M., Runemark, A., Císařová, I. et al (2020). Polycyclizations of Ketoesters: Synthesis of Complex Tricycles with up to Five Stereogenic

Centers from Available Starting Materials. Organic Letters, 22(21): 8387-8391.

http://dx.doi.org/10.1021/acs.orglett.0c03020

N.B. When citing this work, cite the original published paper. 


\title{
Polycyclizations of Ketoesters: Synthesis of Complex Tricycles with up to Five Stereogenic Centers from Available Starting Materials
}

\author{
Martin Kamlar, August Runemark, Ivana Císarová, and Henrik Sundén* \\ Cite This: Org. Lett. 2020, 22, 8387-8391 \\ Read Online
}

ABSTRACT: Here we present a polycyclization of oxotriphenylhexanoates. The polycyclization is governed by electronic effects, and three major synthetic paths have been established leading to stereochemically complex tricyclic frameworks with up to five stereogenic centers. The method is compatible with an array of functional groups, allowing pharmacophoric elements to be introduced post cyclization.
$\mathrm{BBr}_{3}$ promoted mechanistically divergent polycyclization reactions

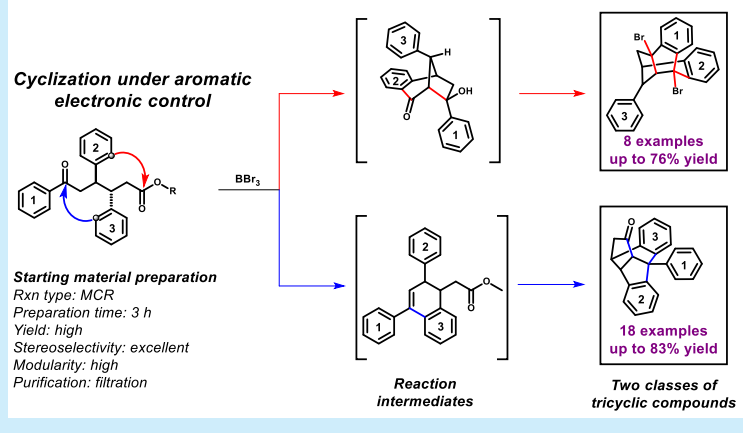

$\mathrm{M}$ orphine, ${ }^{1}$ paclitaxel, $^{2-4}$ strychnine, ${ }^{5}$ or polycyclic terpenes $^{6,7}$ are some examples of natural polycyclic products containing a complex ring system with several stereogenic centers. Polycyclic compounds are interesting because they encode a high degree of molecular information that often makes them selective for a particular biological target. Additionally, polycycles, with a limited number of conformational states, suffer from less entropic loss in ligand binding, making them theoretically more potent binders. ${ }^{8}$ Therefore, construction of polycycles is a highly relevant objective in natural product synthesis and medicinal chemistry research. $^{9-13}$ However, generally synthesis of polycycles is difficult and requires multistep synthesis. ${ }^{1-5,14-16}$ As a consequence most approaches are time-consuming and cost prohibitive, hampering true biological evaluation and, in the end, commercialization. ${ }^{17}$

A way to circumvent synthetic difficulties is to mimic nature and construct a stereospecific polycyclization event where several bonds are set in one step. ${ }^{18,19}$ One early example is the biomimetic polycyclization of progresterone reported by Johnson and co-workers. ${ }^{20}$ In their strategy, a polyolefinic substrate undergoes a stereospecific cyclization cascade to give the core four carbocyclic rings of progesterone. Since then, a number of cascade polycyclizations in natural product synthesis $^{21,22}$ have been designed relying on dearomatizariondriven, ${ }^{23}$ pericyclic, ${ }^{24-32}$ cationic, ${ }^{3-40}$ metal-catalyzed, ${ }^{41-48}$ and radical cascades. ${ }^{49-58}$ Inspired by these strategies, we began investigating the possibility for cyclizing the oxotriphenylhexanoate (OTHO) core. The OTHO is made in a diastereoselective highly modular multicomponent reaction providing a molecular core with two vicinal aryls oriented in an anti-relationship (Figure 1 top). ${ }^{59-62}$ Furthermore, the OTHO

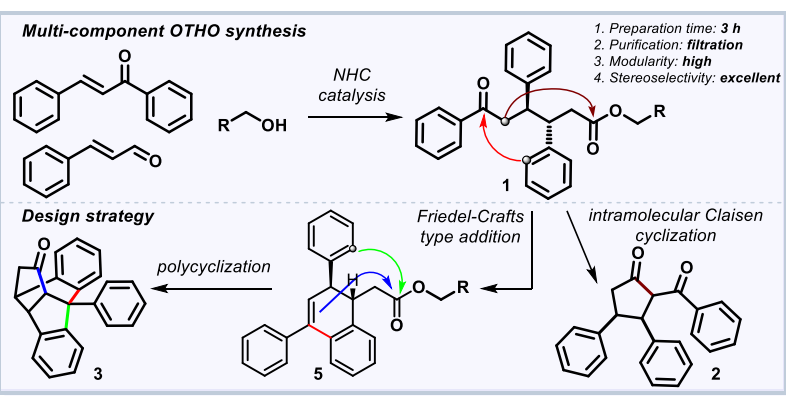

Figure 1. Design plan: two-step synthesis of complex polycycles from readily available starting materials.

is in principle set up for several potential cyclizations with nucleophilic and electrophilic centers distributed five or six carbons apart normally optimal for cyclizations (such as the Dieckmann condensation between the $\alpha$-carbon of the ketone and the ester) (Figure 1). However, we envisioned a design strategy that would start with initial formation of a sixmembered ring through an intramolecular Friedel-Crafts-type addition of Ar3 on the aromatic ketone (red arrow) followed by elimination of the tertiary alcohol to yield olefin 5 . In the next step the double bond undergoes a sequential Lewis

Received: September 9, 2020

Published: October 20, 2020 
activated acylation/aromatic addition to give polycyclic compound 3 (Figure 1 bottom). To evaluate this hypothesis the study commenced with initial screening of different Lewis acids for the cyclization of 1a. While most Lewis acids were inefficient in promoting the transformation (see ESI) $\mathrm{BBr}_{3}$ (1 equiv) proved to be the only productive Lewis acid delivering carbocycle 2a via a Dieckmann condensation in $65 \%$ yield (Table 1 , entry 1 ). At a higher loading of $\mathrm{BBr}_{3}$ (3-5 equiv), a

Table 1. Lewis Acid Mediated Cyclization of 1a

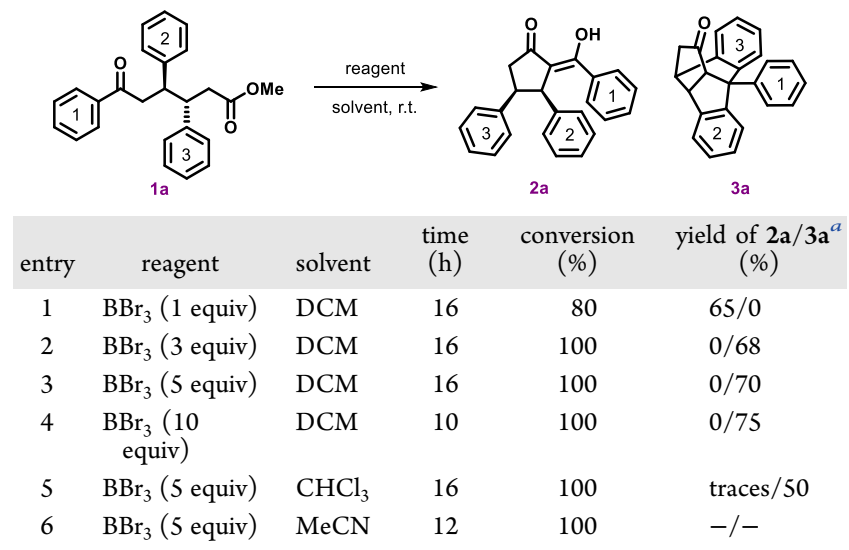

${ }^{a}$ Isolated yield. Reactions were carried out on $0.25 \mathrm{mmol}$ scale of $1 \mathrm{a}$ in a solvent $(3 \mathrm{~mL})$ in a sealed reaction vessel at $\mathrm{rt}$.

cascade of cyclizations took place and tricycle 3 a could be isolated in $68-70 \%$ yield (entries 2 and 3 ). The fastest reaction and highest yield of $3 a(75 \%)$ was observed when 10 equiv of $\mathrm{BBr}_{3}$ was used (entry 4). The reaction performs best in chlorinated solvents, and chloroform can also be used as a reaction solvent (entry 5).

With our optimized conditions in hand, we first tested the efficiency of the domino reaction on a larger reaction scale. It was shown that the cyclization of $1 \mathrm{a}$ in $1 \mathrm{mmol}$ scale proceeded with just a small loss of efficiency and the corresponding product 3 a could be isolated in $72 \%$ yield (compared to $75 \%$ in standard $0.25 \mathrm{mmol}$ reaction scale) (Figure 2). With these results in hand, the scope was explored. First, we examined the effect of substituents on Ar3 (Figure 2). To probe the compatibility with steric bulk, methyl groups were installed on all position of Ar3 in OTHO 1. It can be seen that Ar3 can be substituted on all positions to deliver tricycle 3 in generally excellent yield. For instance, methyl-substituted $\mathbf{3 b}$ can be isolated in $75 \%$ yield (which corresponds to $91 \%$ per bond formed). The most difficult substrate in the series was $1 \mathrm{~d}$ with $o-\mathrm{Me}$ on $\mathrm{Ar} 3$. The low yield (30\%) can be explained by a steric effect exerted by the Me in the ortho position and/or that only one of two possible aromatic carbons are available for bond forming. Halogen substituents are also tolerated, and chloro and bromo derivative $\mathbf{3} \mathbf{f}$ and $\mathbf{3 g}$ can be isolated in good yield (68\% and $61 \%)$. Investigating the availability of the Ar2 shows a similar trend with methyl-substituted tetracycles $3 \mathbf{h}, 3 \mathbf{i}$ and $3 \mathbf{j}$ isolated in $47 \%, 51 \%$, and $74 \%$ yield, respectively. For Ar1, both electron-rich and electron-poor substituents are tolerated. For instance, catechol derivative $3 \mathbf{n}$ could be isolated in $42 \%$ yield. In this transformation the $\mathrm{BBr}_{3}$ plays two roles, promoting the polycyclization and deprotection of the dimethylated catechol starting material. Ar1 halogens are also tolerated, and compounds $\mathbf{3 o}, \mathbf{3 p}, \mathbf{3 q}$, and $\mathbf{3 r}$ can be isolated in $52 \%, 48 \%, 42 \%$, and $63 \%$ yield. In the case of the latter tricyclic

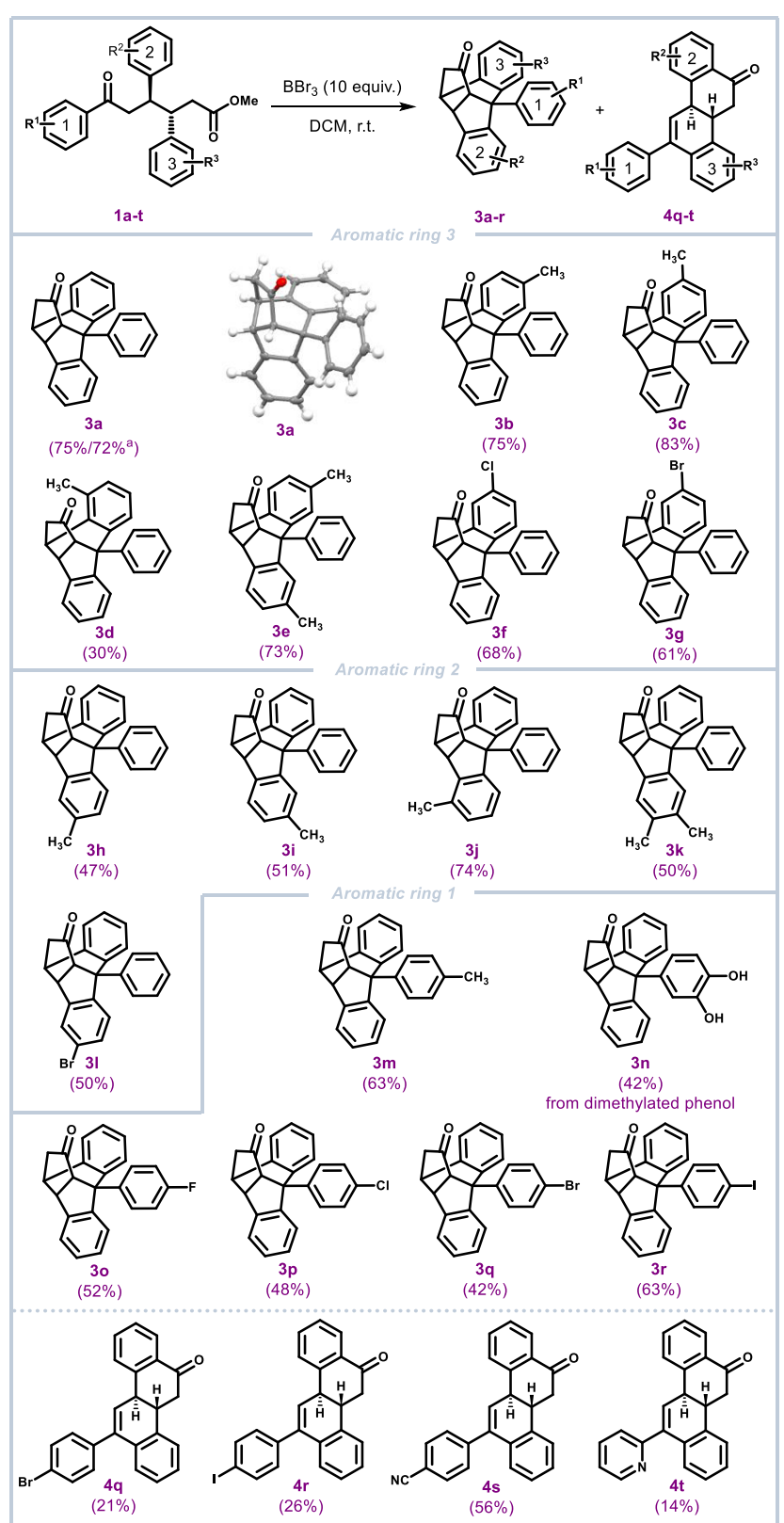

Figure 2. Scope of $\mathrm{BBr}_{3}$-mediated polycyclization of OTHO. Reactions were carried out on a $0.25 \mathrm{mmol}$ scale of 1 in DCM (3 $\mathrm{mL}$ ) in a sealed reaction vessel at rt. (a) $1 \mathrm{mmol}$ scale reaction yield.

compounds dihydrochrysenone derivatives $(4 q-r)$ were isolated as side products. In the case of cyano (1s) and pyridinyl (1t) derivatives dihydrochrysenones $4 \mathbf{s}-\mathbf{t}$ were the only products that could be isolated. The rest of the reaction mixture consisted of unidentified decomposed starting material.

Mechanistically, this finding pointed toward that there are several reaction pathways operational which are under aromatic electronic control. Monitoring the reaction on a gas chromatograph, equipped with a flame ionization detector (GC-FID), showed that, as the OTHO was consumed, there was a buildup of an intermediate that in turn was consumed as the reaction progressed (Figure 3A, yellow line). Stopping the reaction prematurely at $10 \mathrm{~min}$ made it possible to isolate the intermediate, and we could determine the structure to be cyclohexene derivative $\mathbf{5}$. Intermediate $\mathbf{5}$ could also be 


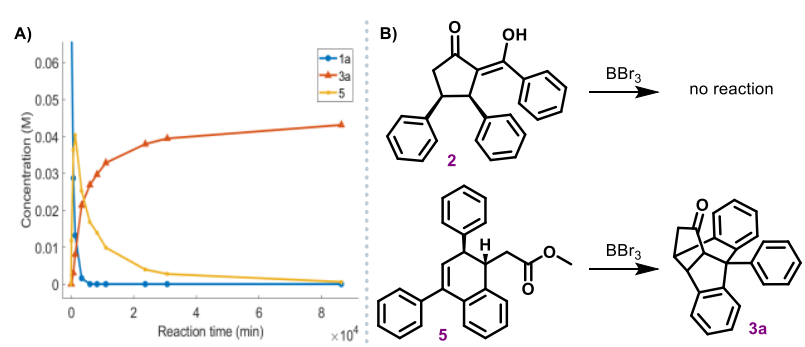

Figure 3. (A) Kinetic plot for the cyclization of 1a. (B) Possible intermediates.

observed in the reaction mixture by NMR (see the Supporting Information). To confirm the notion that $\mathbf{5}$ is the true intermediate product in the cyclization of $\mathbf{1 a}$ intermediate 5 was subjected to 10 equiv of $\mathrm{BBr}_{3}$ to provide $3 \mathrm{a}$ in $51 \%$ yield. These observations lead us to propose the following reaction mechanism (Figure 4). The reaction starts with an intra-

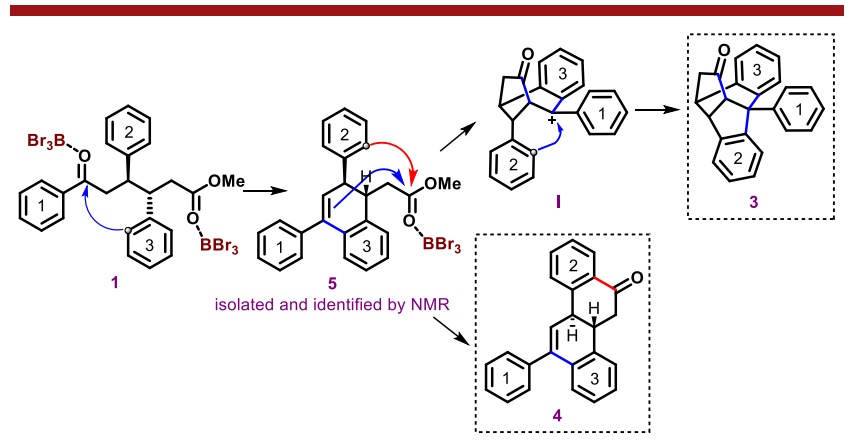

Figure 4. Plausible mechanism scheme for the polycyclization of OTHO leading to derivatives 3 and 4 .

molecular Friedel-Crafts-type addition of Ar3 on the ketone (blue reaction arrow) followed by elimination of the tertiary alcohol to yield olefin $\mathbf{5}$ which can be followed by NMR. In the next step we propose a $\mathrm{BBr}_{3}$ activated acylation/aromatic addition to the double bond to yield the final compound 3 . This is the general reaction pattern and occurs for compounds $3 a-r$. However, with electron-poor Arl the reactivity is drastically shifted with the double bond less prone to react with the ester. Instead an aromatic acylation occurs on Ar2 (red reaction arrow) forming the dihydrochrysenone derivatives $(\mathbf{4 q - \mathbf { s }})$, whereas, when 2 was subjected to 10 equiv of $\mathrm{BBr}_{3}$ no reaction could be observed (Figure 3B). This finding clearly demonstrates that $\mathbf{2}$ is not an intermediate in the synthesis of 3 .

The attentive reader notices that only halogens in the meta position on $\operatorname{Ar} 3$ are represented in Figure 2 (entries $3 f$ and $3 g$ ). The introduction of electron-withdrawing groups on the aromatic ring in the para and ortho position converts the OTHO into a totally different cyclic compound. This was clear after isolation as the ${ }^{13} \mathrm{C}$ NMR was lacking the carbonyl peak. At first the structure of the unknown new product was puzzling considering the very strong effect that was achieved by the placement of the halogen in the starting material (meta vs para compare entries $\mathbf{3 f}, \mathbf{6} \mathbf{b}$ and $\mathbf{3 g}, \mathbf{6 d}$ ). But after solving the structure by NMR and confirming that structure with singlecrystal X-ray diffraction of compound $\mathbf{6 b}$ we could conclude that we have a new tricyclic compound having two bridgehead bromo-atoms. The yield for carbocycle $\mathbf{6}$ is generally good considering that five new bonds are being formed in this one- pot transformation and as a single stereoisomer. The scope was investigated, and the trend is that, as long as an electron withdrawing group is present para or ortho on Ar3 carbocycle 6 will form (Figure 5). For instance, OTHOs with a halogen

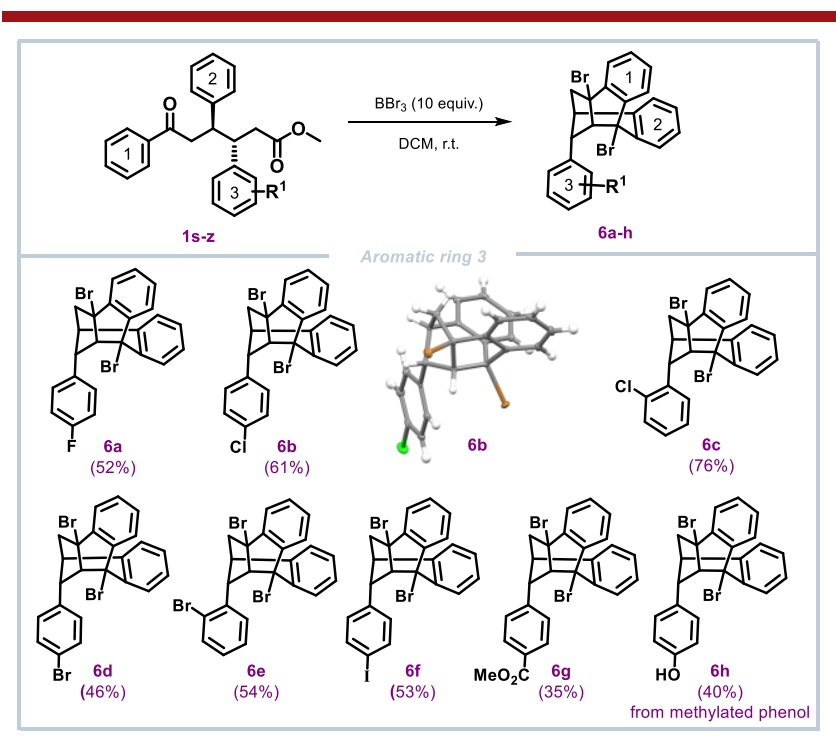

Figure 5. Scope of derivatives 6. Reactions were carried out on 0.25 mmol scale of 1 in DCM $(3 \mathrm{~mL})$ in a sealed reaction vessel at $\mathrm{rt}$.

substituted ortho or para on the aromatic ring will cyclize readily to form compound $\mathbf{6 a - f}$ in yields ranging from 46$76 \%$ yield. Electron withdrawing ester group will also cyclize to give derivative $6 \mathrm{~g}$ in $35 \%$ yield. Interestingly, Ar3 methoxy substituted OTHOs also form carbocycle $\mathbf{6 h}$. This is counterintuitive considering that the methoxy group through electron donation should facilitate the nucleophilic attack on the ketone in the first step. However, this might be an effect of $\mathrm{BBr}_{3}$ complexing the methoxy group or $\mathrm{OH}$ rendering it slightly electron poor thus facilitating the somewhat off-route reaction pattern. Notably, functional groups such as catechol, phenol (entries $3 \mathbf{n}$ and $\mathbf{6 h}$ ) and aromatic carboxylic acid, the later easily derived from $4 \mathrm{~s}$ or $\mathbf{6 g}$, are common pharmacophores providing a step-economical approach to potentially active pharmaceutical ingredients.

Mechanistically, we propose that the formation of $\mathbf{6}$ starts with a Friedel-Craft acylation occurring through a doubly $\mathrm{BBr}_{3}$ activated ketoester. In the first step a reaction between the more reactive nonsubstituted aromatic ring " 2 " and ester group leading to the formation of tetralone II occurs. Next a boron-mediated enol addition to the aromatic carbonyl forms carbocycle III. Following the reaction on GC shows that an intermediate builds up over time and reaches a maximum after $200 \mathrm{~min}$ (see ESI). We believe that this intermediate is derivative III, indirectly verified by NMR after prematurely quenching the reaction forming unsaturated olefinic species IV (Figure 6). In the next step, bromine is introduced through a $\mathrm{BBr}_{3}$ promoted substitution reaction to form $\mathrm{V}$. The slightly larger equatorial bromo substituent forces the aromatic ring closer to the carbonyl and facilitates the attack on the ketone to render the final annulation (VI). Finally, 6 is formed through a $\mathrm{BBr}_{3}$ assisted substitution. ${ }^{63}$ Other domino halocyclizations using boron trihalides have been reported in for instance indene functionalizations ${ }^{64}$ and polycyclic aromatic hydrocarbon synthesis. ${ }^{65}$ 


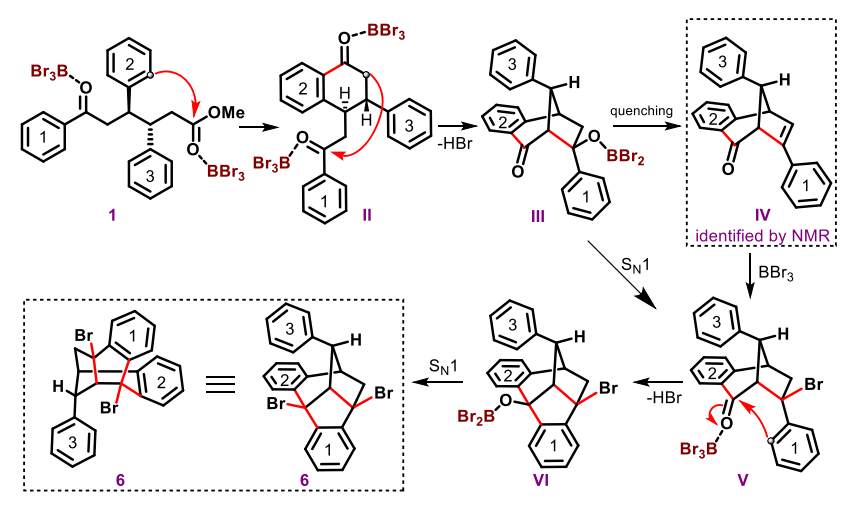

Figure 6. Proposed mechanism of polycyclization of OTHOs leading to derivatives 6 .

The versatility of above prepared derivatives was demonstrated in the following sequence of transformation on dibromo derivatives $\mathbf{6}$. We showed that $\mathbf{6}$ could be orthogonally functionalized using the combination of radical and cross-coupling chemistry (Figure 7). Accordingly, treating

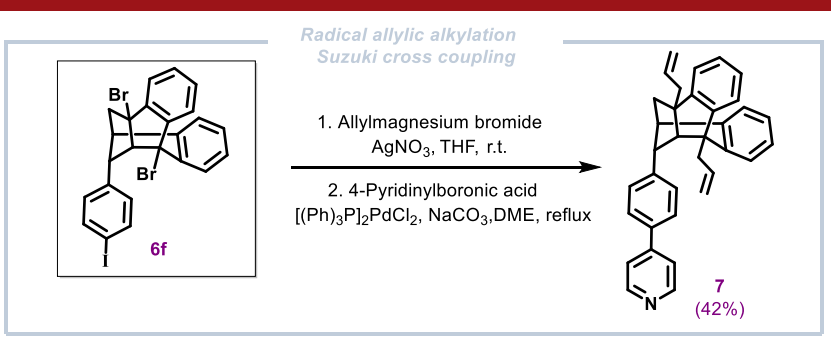

Figure 7. Subsequent transformation of $\mathbf{6 f}$.

6f with allylmagnesium bromide in the presence of silver nitrate gave the corresponding bis-allylated product, ${ }^{66}$ which in turn was directly used in a palladium-catalyzed Suzuki crosscoupling reaction ${ }^{67}$ yielding the doubly functionalized compound 7 in $42 \%$ yield, over two steps, as a single diastereomer. Interestingly, the formation of radicals on the carbon framework does not seem to cause any fragmentation, suggesting that other radical reactions might also be suitable for functionalizing the dibromo-scaffold.

In summary, a straightforward, step-economical route to complex tricyclic molecules with up to five stereogenic centers is presented. The $\mathrm{BBr}_{3}$ promoted stereoselective domino polycyclization relies on easily accessible starting materials (OTHOs) and is compatible with a range of modular aromatic substituents. A systematic investigation of the aromatic substitution pattern of the OTHOs shows that the cyclization is under aromatic electronic control directing the cyclization reaction to either tricyclic molecule 3 or bridgehead dibromo derivative 6. Both types of compound classes are difficult to prepare by any other known methodologies and can potentially be used to position functional groups in space vital, for instance, in the design of biologically active compounds. Lastly, we have also been able to show the possibility of subsequent transformations of polycycles demonstrating the synthetic utility of the protocol.

\section{ASSOCIATED CONTENT}

\section{Supporting Information}

The Supporting Information is available free of charge at https://pubs.acs.org/doi/10.1021/acs.orglett.0c03020.

Experimental details and NMR spectra of synthesized compounds (PDF)

\section{Accession Codes}

CCDC 1989150-1989151 contain the supplementary crystallographic data for this paper. These data can be obtained free of charge via www.ccdc.cam.ac.uk/data_request/cif, or by emailing data_request@ccdc.cam.ac.uk, or by contacting The Cambridge Crystallographic Data Centre, 12 Union Road, Cambridge CB2 1EZ, UK; fax: +44 1223336033.

\section{AUTHOR INFORMATION}

\section{Corresponding Author}

Henrik Sundén - Department of Chemistry and Chemical Engineering, Chalmers University of Technology, 41296 Gothenburg, Sweden; Department of Chemistry and Molecular Biology, University of Gothenburg, SE-412 96 Gothenburg, Sweden; (1) orcid.org/0000-0001-6202-7557; Email: henrik.sunden@chem.gu.se

\section{Authors}

Martin Kamlar - Department of Chemistry and Chemical Engineering, Chalmers University of Technology, 41296 Gothenburg, Sweden; Department of Organic Chemistry, Faculty of Science, Charles University, 12843 Prague 2, Czech Republic

August Runemark - Department of Chemistry and Chemical Engineering, Chalmers University of Technology, 41296 Gothenburg, Sweden; 이이이.org/0000-0002-3650-1881

Ivana Císařová - Department of Inorganic Chemistry, Faculty of Science, Charles University, 12843 Prague 2, Czech Republic

Complete contact information is available at:

https://pubs.acs.org/10.1021/acs.orglett.0c03020

\section{Notes}

The authors declare no competing financial interest.

\section{ACKNOWLEDGMENTS}

The Swedish Research Council Formas is gratefully acknowledged for funding. M.K. thanks the Operational Programme Research, Development and Education, project name: Improvement of internationalization in the field of research and development at Charles University, through the support of quality projects MSCA-IF (reg. no. CZ.02.2.69/0.0/0.0/ 17 050/0008466) for postdoctoral funding.

\section{REFERENCES}

(1) Gates, M.; Tschudi, G. J. Am. Chem. Soc. 1956, 78, 1380-1393.

(2) Nicolaou, K. C.; Yang, Z.; Liu, J. J.; Ueno, H.; Nantermet, P. G.; Guy, R. K.; Claiborne, C. F.; Renaud, J.; Couladouros, E. A.; Paulvannan, K.; Sorensen, E. J. Nature 1994, 367, 630-634.

(3) Holton, R. A.; Somoza, C.; Kim, H. B.; Liang, F.; Biediger, R. J.; Boatman, P. D.; Shindo, M.; Smith, C. C.; Kim, S. J. Am. Chem. Soc. 1994, 116, 1597-1598.

(4) Holton, R. A.; Kim, H. B.; Somoza, C.; Liang, F.; Biediger, R. J.; Boatman, P. D.; Shindo, M.; Smith, C. C.; Kim, S. J. Am. Chem. Soc. 1994, 116, 1599-1600. 
(5) Woodward, R. B.; Cava, M. P.; Ollis, W. D.; Hunger, A.; Daeniker, H. U.; Schenker, K. J. Am. Chem. Soc. 1954, 76, 47494751.

(6) Gershenzon, J.; Dudareva, N. Nat. Chem. Biol. 2007, 3, 408-414.

(7) Hu, P.; Chi, H. M.; DeBacker, K. C.; Gong, X.; Keim, J. H.; Hsu, I. T.; Snyder, S. A. Nature 2019, 569, 703-707.

(8) Fang, Z.; Song, Y. n.; Zhan, P.; Zhang, Q.; Liu, X. Future Med. Chem. 2014, 6, 885-901.

(9) Schreiber, S. L. Science 2000, 287, 1964-1969.

(10) Galloway, W. R. J. D.; Isidro-Llobet, A.; Spring, D. R. Nat. Commun. 2010, 1, 80.

(11) O' Connor, C. J.; Beckmann, H. S. G.; Spring, D. R. Chem. Soc. Rev. 2012, 41, 4444-4456.

(12) Kuznetsov, D. M.; Kutateladze, A. G. J. Am. Chem. Soc. 2017, 139, 16584-16590.

(13) Plesniak, M. P.; Garduño-Castro, M. H.; Lenz, P.; Just-Baringo, X.; Procter, D. J. Nat. Commun. 2018, 9, 4802.

(14) Corey, E. J.; Desai, M. C.; Engler, T. A. J. Am. Chem. Soc. 1985, 107, 4339-4341.

(15) Bonjoch, J.; Solé, D. Chem. Rev. 2000, 100, 3455-3482.

(16) Lee, H.; Kang, T.; Lee, H.-Y. Angew. Chem., Int. Ed. 2017, 56, 8254-8257.

(17) Nicolaou, K. C.; Sorensen, E. J. Classics in Total Synthesis: Targets, Strategies, Methods; Wiley, 1996.

(18) Tietze, L. F. Chem. Rev. 1996, 96, 115-136.

(19) Tietze, L. F.; Brasche, G.; Gericke, K. M. Domino Reactions in Organic Synthesis; Wiley-VCH, 2006.

(20) Johnson, W. S. Angew. Chem., Int. Ed. Engl. 1976, 15, 9-17.

(21) Anderson, E. A. Org. Biomol. Chem. 2011, 9, 3997-4006.

(22) Ardkhean, R.; Caputo, D. F. J.; Morrow, S. M.; Shi, H.; Xiong, Y.; Anderson, E. A. Chem. Soc. Rev. 2016, 45, 1557-1569.

(23) Powers, Z.; Scharf, A.; Cheng, A.; Yang, F.; Himmelbauer, M.; Mitsuhashi, T.; Barra, L.; Taniguchi, Y.; Kikuchi, T.; Fujita, M.; Abe, I.; Porco, J. A., Jr Angew. Chem., Int. Ed. 2019, 58, 16141-16146.

(24) Shishido, K.; Shitara, E.; Komatsu, H.; Hiroya, K.; Fukumoto, K.; Kametani, T. J. Org. Chem. 1986, 51, 3007-3011.

(25) Danishefsky, S. J.; DeNinno, M. P. Angew. Chem., Int. Ed. Engl. 1987, 26, 15-23.

(26) Mikami, K.; Takahashi, K.; Nakai, T. J. Am. Chem. Soc. 1990, 112, 4035-4037.

(27) Knight, S. D.; Overman, L. E.; Pairaudeau, G. J. Am. Chem. Soc. 1993, 115, 9293-9294.

(28) Angle, S. R.; Fevig, J. M.; Knight, S. D.; Marquis, R. W.; Overman, L. E. J. Am. Chem. Soc. 1993, 115, 3966-3976.

(29) Denmark, S. E.; Thorarensen, A. J. Org. Chem. 1994, 59, 56725680.

(30) Mikami, K.; Takahashi, K.; Nakai, T.; Uchimaru, T. J. Am. Chem. Soc. 1994, 116, 10948-10954.

(31) Deng, W.; Overman, L. E. J. Am. Chem. Soc. 1994, 116, 1124111250 .

(32) Poulin, J.; Grisé-Bard, C. M.; Barriault, L. Chem. Soc. Rev. 2009, 38, 3092-3101.

(33) Jacobsen, E. J.; Levin, J.; Overman, L. E. J. Am. Chem. Soc. 1988, 110, 4329-4336.

(34) O’Hagan, D. Nat. Prod. Rep. 1989, 6, 205-219.

(35) Bartlett, W. R.; Johnson, W. S.; Plummer, M. S.; Small, V. R. J. Org. Chem. 1990, 55, 2215-2224.

(36) Snowden, R. L.; Eichenberger, J. C.; Linder, S. M.; Sonnay, P.; Vial, C.; Schulte-Elte, K. H. J. Org. Chem. 1992, 57, 955-960.

(37) Fish, P. V.; Johnson, W. S. J. Org. Chem. 1994, 59, 2324-2335.

(38) Beifuss, U.; Ledderhose, S. Synlett 1995, 1995, 938-940.

(39) Koert, U. Angew. Chem., Int. Ed. Engl. 1995, 34, 298-300.

(40) Barrett, T. N.; Barrett, A. G. M. J. Am. Chem. Soc. 2014, 136, 17013-17015.

(41) Dombroski, M. A.; Kates, S. A.; Snider, B. B. J. Am. Chem. Soc. 1990, 112, 2759-2767.

(42) Porco, J. A.; Schoenen, F. J.; Stout, T. J.; Clardy, J.; Schreiber, S. L. J. Am. Chem. Soc. 1990, 112, 7410-7411.
(43) Dauben, W. G.; Dinges, J.; Smith, T. C. J. Org. Chem. 1993, 58, $7635-7637$.

(44) Boyer, F.-D.; Hanna, I.; Ricard, L. Org. Lett. 2004, 6, 18171820.

(45) Pinto, A.; Jia, Y.; Neuville, L.; Zhu, J. Chem. - Eur. J. 2007, 13, 961-967.

(46) Mai, W.-P.; Sun, G.-C.; Wang, J.-T.; Song, G.; Mao, P.; Yang, L.-R.; Yuan, J.-W.; Xiao, Y.-M.; Qu, L.-B. J. Org. Chem. 2014, 79, 8094-8102.

(47) Hao, T.-T.; Liang, H.-R.; Ou-Yang, Y.-H.; Yin, C.-Z.; Zheng, X.-L.; Yuan, M.-L.; Li, R.-X.; Fu, H.-Y.; Chen, H. J. Org. Chem. 2018, $83,4441-4454$.

(48) Pellissier, H. Adv. Synth. Catal. 2019, 361, 1733-1755.

(49) Corey, E. J.; Kang, M. C. J. Am. Chem. Soc. 1984, 106, 53845385.

(50) Fevig, T. L.; Elliott, R. L.; Curran, D. P. J. Am. Chem. Soc. 1988, $110,5064-5067$.

(51) Curran, D. P.; Liu, H. J. Am. Chem. Soc. 1992, 114, 5863-5864.

(52) Hitchcock, S. A.; Pattenden, G. Tetrahedron Lett. 1992, 33, $4843-4846$.

(53) Chen, L.; Gill, G. B.; Pattenden, G. Tetrahedron Lett. 1994, 35, $2593-2596$

(54) Takahashi, T.; Katouda, W.; Sakamoto, Y.; Tomida, S.; Yamada, H. Tetrahedron Lett. 1995, 36, 2273-2276.

(55) Sebren, L. J.; Devery, J. J.; Stephenson, C. R. J. ACS Catal. 2014, 4, 703-716.

(56) Plesniak, M. P.; Huang, H.-M.; Procter, D. J. Nat. Rev. Chem. 2017, 1, 0077.

(57) Wang, X.; Xia, D.; Qin, W.; Zhou, R.; Zhou, X.; Zhou, Q.; Liu, W.; Dai, X.; Wang, H.; Wang, S.; Tan, L.; Zhang, D.; Song, H.; Liu, X.-Y.; Qin, Y. Chem. 2017, 2, 803-816.

(58) Hung, K.; Hu, X.; Maimone, T. J. Nat. Prod. Rep. 2018, 35, 174-202.

(59) Nair, V.; Babu, B. P.; Vellalath, S.; Varghese, V.; Raveendran, A. E.; Suresh, E. Org. Lett. 2009, 11, 2507-2510.

(60) Ta, L.; Axelsson, A.; Bijl, J.; Haukka, M.; Sunden, H. Chem. Eur. J. 2014, 20, 13889-13893.

(61) Axelsson, A.; Ta, L.; Sunden, H. Catalysts 2015, 5, 2052-2067.

(62) Sauvée, C.; Ström, A.; Haukka, M.; Sundén, H. Chem. - Eur. J. 2018, 24, 8071-8075.

(63) Pelletier, J. D.; Poirier, D. Tetrahedron Lett. 1994, 35, 10511054.

(64) Sultana, S.; Lee, Y. R. Adv. Synth. Catal. 2020, 362, 927-941.

(65) Yuan, K.; Kahan, R. J.; Si, C.; Williams, A.; Kirschner, S.; Uzelac, M.; Zysman-Colman, E.; Ingleson, M. J. Chem. Sci. 2020, 11, $3258-3267$.

(66) Someya, H.; Ohmiya, H.; Yorimitsu, H.; Oshima, K. Org. Lett. 2008, 10, 969-971.

(67) Bower, J. F.; Guillaneux, D.; Nguyen, T.; Wong, P. L.; Snieckus, V. J. Org. Chem. 1998, 63, 1514-1518. 